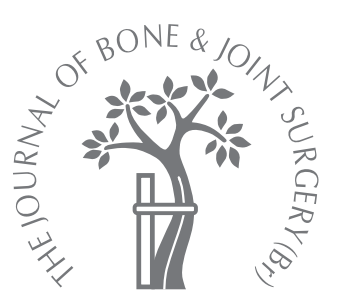

C.W.B. Steinlechner, N. C. Mkandawire

From Beit Trust CURE International Hospital, Blantyre, Malawi

C. W. B. Steinlechner, BSc(Hons), MBBS, FRCS(Eng), FRCS(Tr \& Orth), Consultant Orthopaedic Surgeon

North Devon District Hospital, Raleigh Hill, Barnstaple, Devon EX31 4JB, UK.

N. C. Mkandawire, MCh(Orth), FCS(ECSA), Senior Lecturer, Consultant Orthopaedic Surgeon Department of Surgery University of Malawi, College of Medicine, P/B 360, Chichiri, Blantyre 3, Malawi.

Correspondence should be sent to Dr. N. C. Mkandawire; e-mail:

ncmkandawire@malawi.net

(C)2005 British Editorial

Society of Bone and

Joint Surgery

doi:10.1302/0301-620X.87B9.

$15734 \$ 2.00$

$J$ Bone Joint Surg $[\mathrm{Br}]$ 2005;87-B:1259-63.

Received 16 June 2004

Accepted after revision

5 May 2005

\title{
Non-vascularised fibular transfer in the management of defects of long bones after sequestrectomy in children
}

The management of chronic osteomyelitis requires the excision of necrotic and infected material followed by the prolonged administration of antibiotics. Sequestrectomy may be required before an involucrum has formed, resulting in a longitudinal bone defect. This can be difficult to fill. Vascularised grafts are complicated by a high rate of recurrent infection and thrombosis.

We have managed defects of long bones in children after sequestrectomy by the use of non-vascularised fibular grafts harvested subperiosteally and held by an intramedullary Kirschner wire. Eight children underwent this procedure. In six the tibia was involved and in one each the humerus and radius. One patient was lost to follow-up. Six grafts united at both ends within 12 weeks. The seventh developed an infected nonunion distally which united after further debridement. One patient required a further sequestrectomy which did not compromise union.

We have found this to be a straightforward technique with reliable results and were able to salvage the limb in all the seven patients who were reviewed.

In the treatment of chronic osteomyelitis a sequestrectomy may lead to a considerable bony defect (Figs 1 and 2), which is difficult to fill. Vascularised grafts are complicated by a low rate of primary union and a high rate of infection and thrombosis. ${ }^{1-4}$ We have used a non-vascularised fibular graft to fill this gap and describe the outcome in eight patients.

\section{Patients and Methods}

There were three boys and five girls, with a mean age of 6 years 2 months (2 to 14). One patient was lost to follow-up before bony union was achieved. The bones involved were the tibia in six (one lost to follow-up), the humerus in one and the radius in one.

Details of the seven patients who were reviewed are given in Table I.

After sequestrectomy, the patients were kept in hospital on bed rest and with the debrided limb elevated and supported by a plaster splint. Infections were treated with chloramphenicol, which was the only antibiotic available. The wounds were inspected regularly and secondary closure undertaken when the infection had clinically resolved. The use of inflammatory markers would have been helpful but were not available.

Once clinically free from infection, fibular grafting was performed. When the tibia was involved, the graft was harvested from the ipsilateral limb. The sequestrectomy, harvesting of the graft and transfer were all performed through the same anterolateral incision. The mean time from sequestrectomy to grafting was 5.7 weeks (4 to 8 ). When the defect was in the upper limb, the fibula was harvested through a lateral approach. In each case it was harvested subperiosteally, transferred to the recipient site and held in a place using a single intramedullary Kirschner (K-) wire (Fig. 3). This was introduced into the tibia through the heel and into the upper limb through the radial styloid or the proximal humerus. The limbs were additionally supported in below-knee, above-elbow or U-slab plaster splints. The patients continued on bed rest until the wounds had healed. Nonweight-bearing mobilisation was then allowed.

The patients were reviewed regularly until union was achieved. At this stage the K-wire was removed and progressive mobilisation begun. The length of follow-up was determined by the willingness of the patient's relatives to travel to the clinic.

\section{Results}

We were able to follow-up seven of the eight patients. The mean length of the fibular graft 


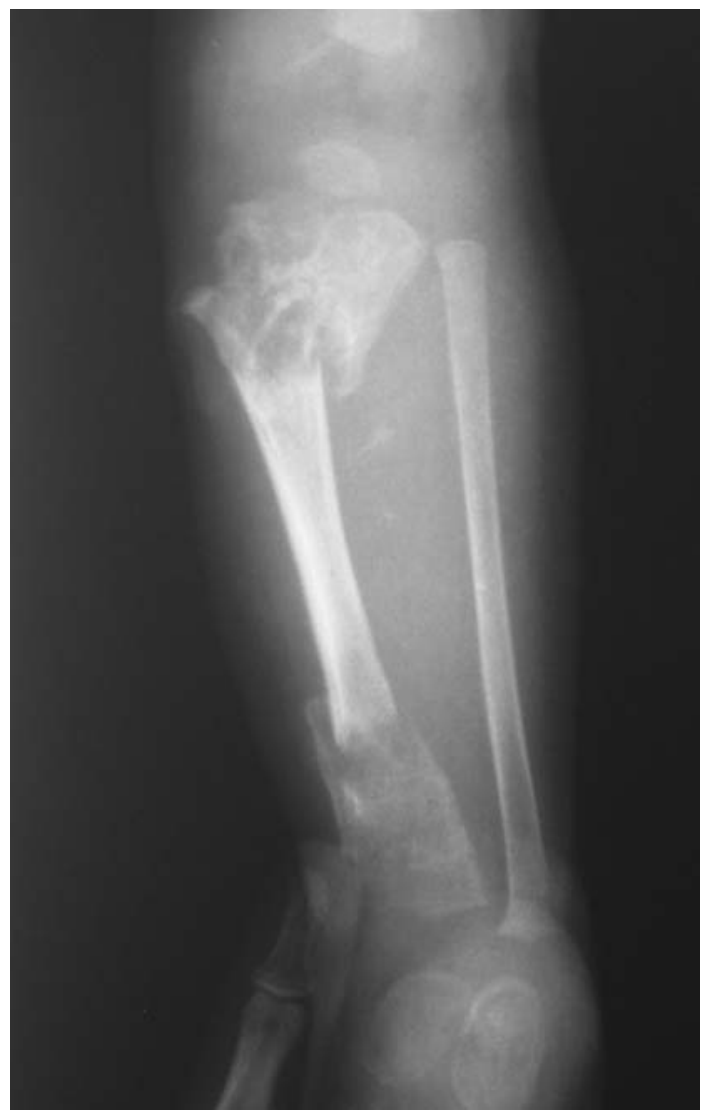

Fig. 1

Radiograph showing chronic osteomyelitis of the tibia with a large sequestrum and no bridging involucrum.

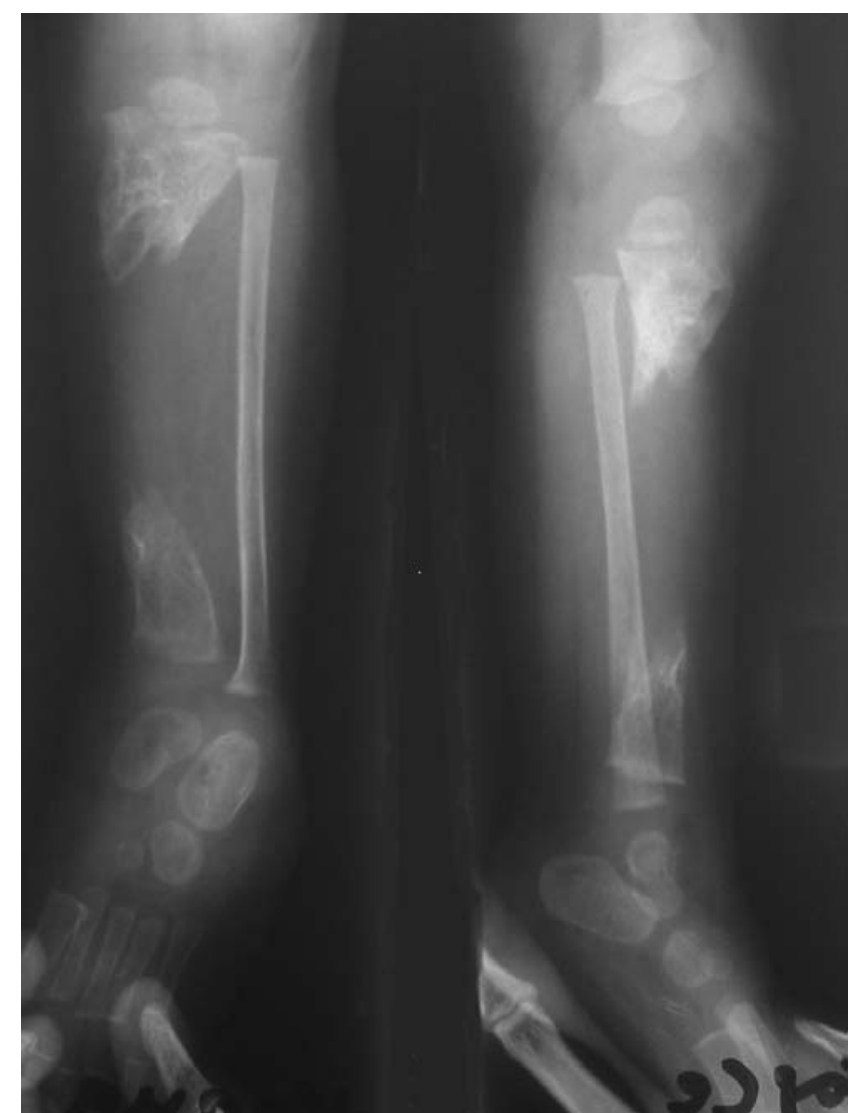

Fig. 2

Radiograph showing the defect after sequestrectomy.

sequestrectomy which did not compromise bony continuity.

Regrowth of the fibula occurred in six patients (Figs 4 and 5) but in the seventh (case 4) cross-union occurred between the tibia and fibula.

The patients were advised to mobilise non-weight-bearing until union, but examination of the plaster casts showed that full use had been made of the operated limb before the first outpatient review.

Five of the seven patients failed to attend further followup after union because of financial, distance and time con-

Table I. Details and results in seven patients

\begin{tabular}{|c|c|c|c|c|c|c|c|}
\hline Case & Mean age & Gender & Bone involved & $\begin{array}{l}\text { Mean interval from } \\
\text { sequestrectomy to } \\
\text { grafting (wks) }\end{array}$ & $\begin{array}{l}\text { Mean time to } \\
\text { union (wks) }\end{array}$ & Graft length $(\mathrm{cm})$ & Further procedures \\
\hline 1 & 4 yrs & $\mathrm{M}$ & Tibia & 6 & 6 & 4.7 & \\
\hline 2 & 6 yrs & $\mathrm{F}$ & Tibia & 6 & 8 & 12.0 & \\
\hline 3 & 2 yrs & $\mathrm{F}$ & Tibia & 8 & 75 & 6.8 & \\
\hline 4 & 8 mths & $\mathrm{F}$ & Tibia & 4 & 10 & 5.4 & Debridement \\
\hline 5 & 12 yrs & $\mathrm{F}$ & Tibia & 4 & 12 & 4.5 & \\
\hline 6 & 14 yrs & $\mathrm{F}$ & Radius & 6 & 12 & 4.0 & Sequestrectomy \\
\hline 7 & 4 yrs & $\mathrm{M}$ & Humerus & 6 & 12 & 11.6 & \\
\hline
\end{tabular}




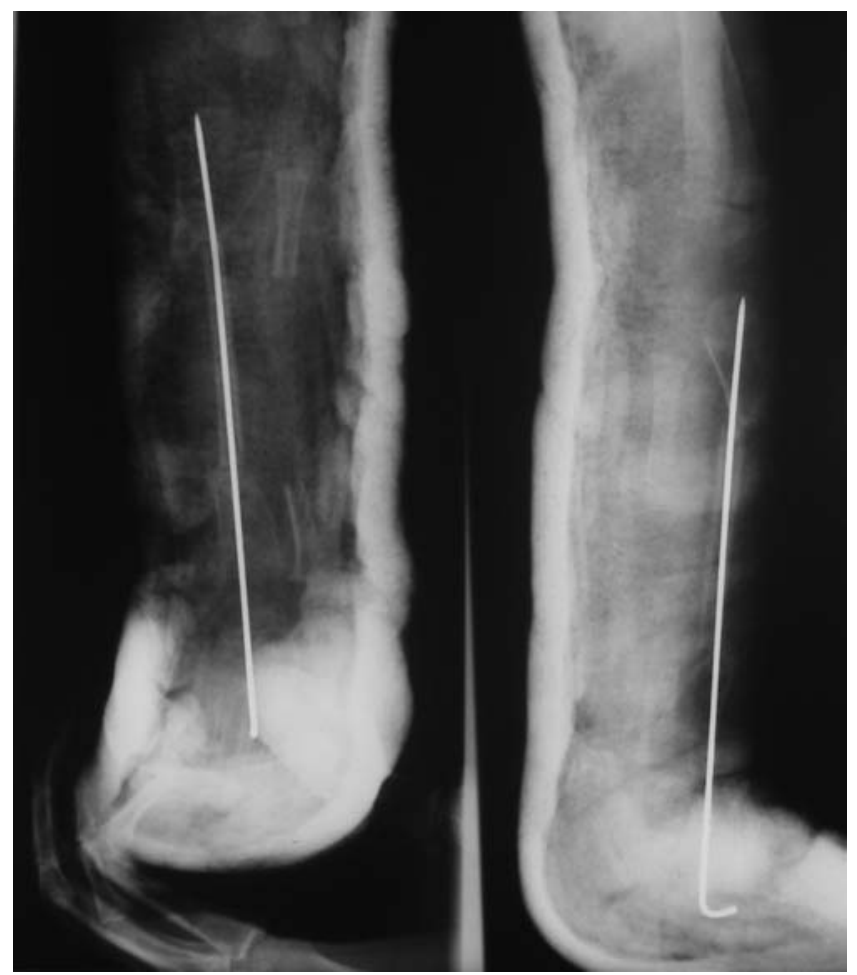

Fig. 3

Radiograph showing a fibular graft stabilised by an intramedullary Kirschner wire.

straints. Two patients (cases 4 and 5) continue to attend. One (case 6) is walking freely seven months after fibular transfer and has a full range of movement of both knee and ankle in the operated limb, although it is $1 \mathrm{~cm}$ shorter than the contralateral leg (Fig. 6).

\section{Discussion}

Chronic osteomyelitis is a cause of considerable morbidity, particularly in the juvenile skeleton when it may lead to limb-length inequality secondary to growth arrest or bony overgrowth. ${ }^{5}$ Eradication of the infection requires excision of all infected bone followed by prolonged administration of antibiotics. Usually, sequestrectomy is delayed until a bridging involucrum has formed, but when the sequestrum is protruding through the skin and there is a large amount of pus or the patient is systemically compromised, urgent sequestrectomy may be required resulting in a considerable longitudinal bony defect. Severe damage to the periosteum may prevent an involucrum from forming. ${ }^{4}$

The filling of a bony defect after infection can be a challenge. A high rate of complications and a rate of primary union of as low as $48 \%$ have been reported. ${ }^{3}$ Various methods have been used including bone transport or segmental bone grafts, usually from the iliac crest or fibula. Segmental bone grafts may be non-vascularised or vascularised pedicle or free grafts. ${ }^{1-4,6-11}$ The advantage of vascularised grafts is that they do not rely on re-vascularisation

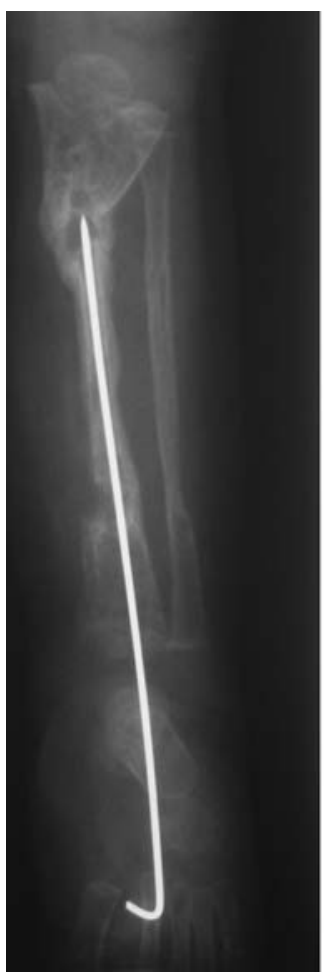

Fig. 4a

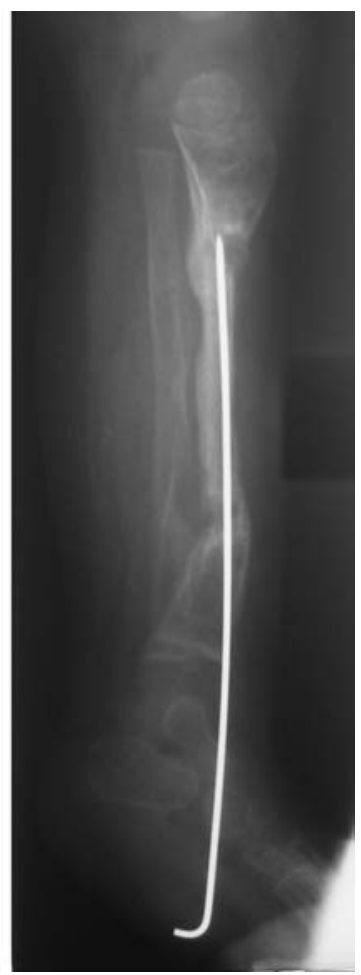

Fig. $4 b$
Radiographs showing bony union and fibular regrowth.

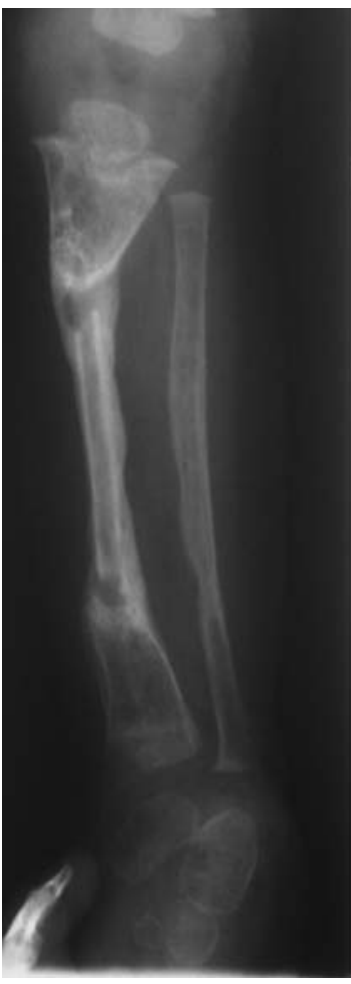

Fig. $5 a$

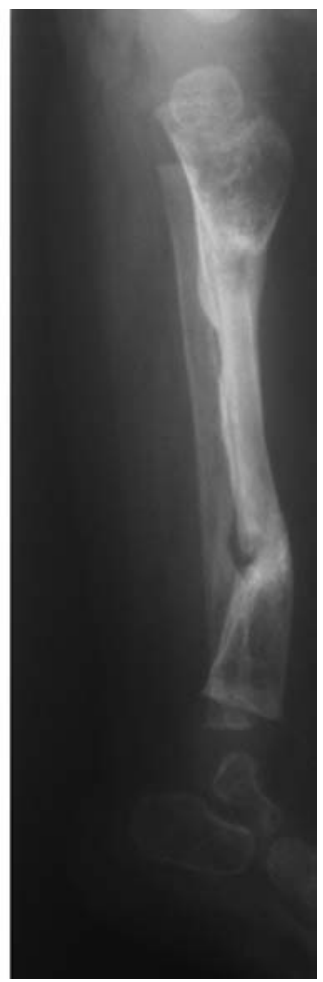

Fig. 5b
Radiographs showing consolidation of bony union of both the tibia and fibula. 


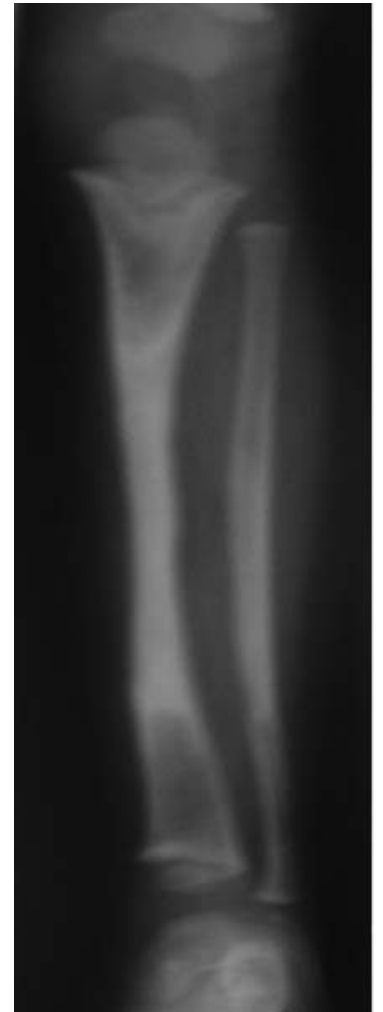

Fig. 6a

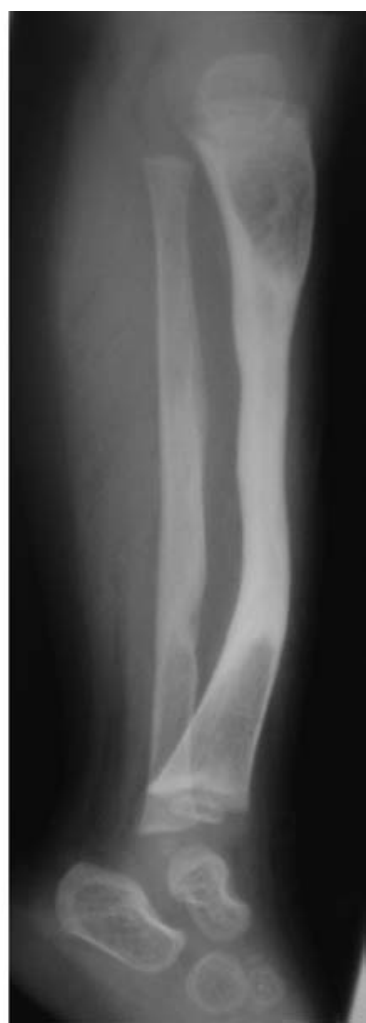

Fig. $6 b$
Radiographs showing the fibular graft fully incorporated and consolidated. After eight months the patient was fully mobile.

and therefore should become fully incorporated sooner. However, it is a technically demanding procedure with a high rate of thrombosis of the graft vessels. ${ }^{6,7}$ Non-vascularised grafts are technically much easier to use and have been successful in children and adults, but they may take many months to be incorporated during which time they lose much of their strength and are susceptible to fracture. ${ }^{2,4}$ Morcellised bone graft has also been used with some success, relying on creeping substitution to achieve union. Tibial defects of up to $14 \mathrm{~cm}$, following open fractures, have been managed by this technique, taking six to 14 months to achieve radiological union. ${ }^{10}$

When fibular grafting has been undertaken for osteomyelitis or infected nonunion, rates of infection of up to $57 \%$ have been reported. ${ }^{1}$ Even with a previously sterile surgical field infection may lead to loss of the graft. ${ }^{2,3}$ Further complications include fracture of the graft, development of a compartment syndrome, nerve damage and muscle tethering. $1,3,9$

Donor-site morbidity is also common. Gore et $\mathrm{al}^{12}$ reported that "most patients will have subjective complaints and mild muscle weakness after removal of a portion of the fibula". Excision of a segment of fibula has been shown to lead to proximal migration of the lateral malleolus and accompanying valgus tilt, these being statistically linked. ${ }^{13}$
In view of the possibility of morbidity from the donor site when the tibia was being treated, the fibula was harvested from the ipsilateral limb. Although this risks further destabilisation of the limb, in the developing world malrotation or shortening of the salvaged limb is well tolerated whereas damage to the normal limb may not be.

In our series, the fibula was harvested subperiosteally and six fibulae showed regrowth. The seventh did not regrow in continuity, but formed a cross-union with the tibia, thereby achieving bony stability. With the abnormal anatomy which occurs after sequestrectomy, it was impossible to analyse the talar angle formally, but given the restoration of bony continuity, we expect the fibula to regain its function in stabilising the ankle. Another advantage of fibular regrowth is its availability for further bone grafting.

Our rate of infection of $29 \%$ was higher than we would like, but these procedures were performed in a setting where careful monitoring of inflammatory markers and accurate microbiological diagnosis were not possible and the choice of antibiotics was very limited.

One patient failed to return for follow-up. There is only one other orthopaedic surgeon in Malawi who is located several hundred miles away. Therefore, it is unlikely that the patient would have presented elsewhere. There is a high tolerance of morbidity and a high mortality rate and therefore it is not possible to know whether this graft had incorporated. The difficulties of long-term follow-up and the impossibility of postal surveys do not allow comments to be made on the occurrence of subsequent graft fractures. None has occurred to our knowledge, but they may have been managed conservatively locally.

The use of fibular grafts harvested subperiosteally in the management of defects of long bones is a relatively straightforward procedure, requiring no microsurgical expertise. Immediate bony stability is achieved by the use of an intramedullary K-wire. Bony union may take many months in both adults ${ }^{2}$ and children. Union was achieved in six of seven children within 12 weeks. Infection of the graft occurred in two patients delaying bony union in one for 75 weeks. In both it was ultimately controlled and limb salvage achieved. In general, we have found this to be a very useful technique in children.

No benefits in any form have been received or will be received from a commercial party related directly or indirectly to the subject of this article.

\section{References}

1. Jupiter JB, Bour CJ, May JW Jr. The reconstruction of defects in the femoral shaft with vascularised transfers of bone. J Bone Joint Surg [Am] 1987;69-A:365-74.

2. Ennecking WF, Eady JL, Burchardt H. Autogenous bone grafts in the reconstruction of segmental skeletal defects. J Bone Joint Surg [Am] 1980;62-A:1039-58.

3. Han C-S, Wood MB, Bishop AT, Cooney WP 3rd. Vascularised bone transfer. J Bone Joint Surg [Am] 1992;74-A:1441-9.

4. Daoud A, Saighi-Bouaouina A. Treatment of sequestra, pseudarthrosis and defects in the long bones of children who have chronic haematogenous osteomyelitis. J Bone Joint Surg [Am] 1989;71-A:1448-68.

5. Bates J. Bone overgrowth in chronic osteomyelitis in children. Procs Association of Surgeons of East Africa conference 2003. 
6. Yajima H, Tamai S, Mizumoto S, Inada Y. Vascularised fibular grafts in the treatment of osteomyelitis and infected non-union. Clin Orthop 1993;293:256-64.

7. Minami A, Kasashima T, Iwasaki N, Kato H, Kaneda K. Vascularised fibular grafts. J Bone Joint Surg [Br]2000;82-B:1022-5.

8. Cattaneo R, Catagni M, Johnson EE. The treatment of infected nonunions and segmental defects of the tibia by methods of Ilizarov. Clin Orthop 1992;280:143-52.

9. Yadav SS. Dual-fibular grafting for massive bone gaps in the lower extremity. J Bone Joint Surg [Am] 1990;72-A:486-94.
10. Christian EP, Bosse MJ, Robb G. Reconstruction of large diaphyseal defects, without free fibular transfer, in grade-Illb tibial defects. J Bone Joint Surg [Am]1989;71-A:994-1004.

11. Atkins RM, Madhavan P, Sudhakar J, Whitwell D. Ipsilateral vascularised fibular transport for massive defects of the tibia. J Bone Joint Surg [Br] 1999;81-B:1035-40.

12. Gore DR, Gardner GM, Sepic SB, Mollinger LA, Murray MP. Function following partial fibulectomy. Clin Orthop 1987;220:206-10.

13. Gonzalez-Heranz P, del Rio A, Burgos J, Lopez-Mondejar JA, Rapariz JM. Valgus deformity after fibular resection in children. J Paed Orthop 2003;23:55-9. 